\title{
Application of Model Predictive Control to Renewable Energy Development via Reactive Distillation Process
}

\author{
Saidat Olanipekun GIWA ${ }^{1, a}$, Abel Adekanmi ADEYI ${ }^{2, b}$ \\ and Abdulwahab GIWA ${ }^{3, c^{*}}$ \\ ${ }^{1}$ Chemical Engineering Department, Faculty of Engineering and Engineering Technology, \\ Abubakar Tafawa Balewa University, Tafawa Balewa Way, Bauchi, Nigeria \\ ${ }^{2}$ Chemical and Petroleum Engineering Department, College of Engineering, Afe Babalola \\ University, Afe Babalola Way, Ado-Ekiti, Ekiti State, Nigeria \\ ${ }^{3}$ Chemical and Petroleum Engineering Department, College of Engineering, Afe Babalola \\ University, Afe Babalola Way, Ado-Ekiti, Ekiti State, Nigeria \\ asogiwa@atbu.edu.ng, babeladeyi@abuad.edu.ng, ’agiwa@abuad.edu.ng
}

\begin{abstract}
Keywords: Renewable energy, reactive distillation, MATLAB, modelling and simulation, model predictive control (MPC).
\end{abstract}

\begin{abstract}
Reactive distillation is a process that combines chemical reaction and separation in a single piece of equipment (distillation column). The process has a lot of benefits especially for those reactions occurring at conditions suitable for the distillation of the process components, and these result in significant economic advantages. However, owing to the complexities resulting from the integration of reaction and separation, its control is still a challenge to process engineers because it requires a control method that is robust enough to handle its complexities. Therefore, in this work, model predictive control (MPC) has been applied to a reactive distillation process used for developing a renewable energy known as biodiesel. The control algorithm of the MPC was formulated with the aid of MPC toolbox of MATLAB/Simulink in which the closed-loop models of the process were developed and simulated. The analysis of the results obtained from the simulations carried out for the optimization of the tuning parameters revealed that, among the tuning parameters considered, integral absolute error of the control system was less affected by the control horizon because its p-value was greater than 0.05 based on $95 \%$ confidence level. Furthermore, the simulation of the closed-loop system of the process using model predictive control tuned with control horizon of 11 , prediction horizon of 18, weight on manipulated variable rate of 0.05 and weight on output variable of 2.17, which were the optimum parameters obtained using Excel Solver, showed that the system was well handled by the controller under servo control because it was able to get settled at desired mole fractions within $60 \mathrm{~min}$. However, the settling time recorded in the case of regulatory control system of the process with the same controller was found not to be encouraging. Therefore, it is recommended that further work should be carried out on this subject matter in an attempt to obtain tuning parameters that will make the settling time of the closed-loop system of the process under regulatory control simulation very reasonable.
\end{abstract}

\section{Nomenclature}

$\begin{array}{ll}\text { ANOVA } & \text { Analysis of variance } \\ \text { DMC } & \text { Dynamic matrix control } \\ \mathrm{G}_{\mathrm{p}} & \text { Transfer function model of the process } \\ \mathrm{GPC} & \text { Generalized predictive control } \\ \mathrm{IAE} & \text { Integral absolute error } \\ \mathrm{ISE} & \text { Integral squared error } \\ \mathrm{K}_{\mathrm{p}} & \text { Static gain of the transfer function model of the process } \\ \text { MAC } & \text { Model algorithmic control } \\ \text { MPC } & \text { Model predictive control(ler) } \\ \mathrm{PI} & \text { Proportional-integral }\end{array}$




$\begin{array}{ll}\text { PID } & \text { Proportional-integral-derivative } \\ \mathrm{Q}_{\text {reb }}, \mathrm{Q} & \text { Reboiler heat duty }(\mathrm{kJ} / \mathrm{s}) \\ \mathrm{R} & \text { Reflux ratio } \\ \text { wurate } & \text { Weight on manipulated variable rate } \\ \text { wy } & \text { Weight on output variable } \\ \mathrm{x}_{\mathrm{biod}} & \text { Bottom biodiesel mole fraction } \\ \mathrm{T}_{\mathrm{dp}} & \text { Delay time of the transfer function model of the process (min) } \\ \mathrm{T}_{\mathrm{p}} & \text { Time constant of the transfer function model of the process (min) }\end{array}$

\section{Introduction}

There is almost undisputed agreement that energy plays a pivotal role in national development. By and large, there is a high degree of relationship between energy use, economic growth, and level of development. The climate change due to greenhouse gases emissions and turbulence in oil and gas prices have turned global attention to green energy sources, which are environmentally friendly. The major components of the green energy sources are renewable energy types [1].

Renewable energy is a regenerative energy derived from sources that are not prone to depletion in the human time scale, and they include biomass, solar, hydro, and geothermal [2]. These types of energy cannot be exhausted and they constantly and automatically renew.

Biomass, being a renewable organic matter, includes biological material derived from living, or recently living organisms, such as wood, waste, alcohol fuels and biodiesel [2].

Biodiesel, as a renewable energy, is a fuel made from plant oils and can be used in diesel engines [2]. It can be directly used to replace petroleum diesel without modifying diesel engines because their properties are similar [3-9]. Also, it is a promising alternative to conventional petroleum based diesel fuel, and it has a number of other benefits such as reducing carbon dioxide emissions by about 78\%, nontoxicity and biodegradability. These benefits have made biodiesel a very good environmentally benign one. Furthermore, biodiesel has properties that are more superior to those of petro-diesel fuel [8-12] such as nontoxicity [8, 9, 12, 13]. Researches involving the production of biodiesel are being embarked on nowadays because it is very important for today's world to identify an alternative to fossil fuel to meet the future demands for energy $[8,9,12,14-16]$ based on the fact diesel fossil fuel reserves are dwindling and, at a time, they may run out $[8,9,12$, 17] especially for use in internal combustion engines.

Biodiesels are typically made from renewable organic raw materials such as jatropha, soybean or rapeseed oils, animal fats, waste vegetable oils or microalgae oils [2]. Their production methods include direct use and blending, micro emulsions, thermal cracking and esterification/transesterification. Esterification/transesterification is the most popular method of biodiesel production, and in that method, fatty acids/vegetable oils and animal fats are used as feed stocks. The production of biodiesel using esterification/transesterification can, actually, be accomplished via reactive distillation process for improved conversion $[4,6,18]$.

Reactive distillation is a process that is capable of combining both separation and chemical reaction in a single equipment unit [19-22], and it has a lot of advantages especially for those reactions occurring at suitable and appropriate conditions for the distillation of the reaction components $[4,5,20,23-30]$. Apart from that, this process combines the benefits of equilibrium reaction with distillation in order to achieve a substantial progress in promoting reaction conversion as a result of constant recycling of unconverted materials and removal of products. As such, the process is able to reduce capital and operating costs as a result of the reduction that occurs in the number of equipment units of the plant [4, 30-32]. In addition to the advantages mentioned before, basically, the combination of reaction and distillation in the same equipment unit gives rise to suppression of side reaction(s) and utilization of heat evolved from an exothermic reaction for mass transfer operation. These synergistic effects of the process result in low energy cost and high product yields $[30,33]$. However, as a result of combining reaction and separation in a single piece of equipment in this process, its control has been a challenge to process engineers because it must 
be handled using a robust control method that will be able to take care of the complexities involved in it. This is the reason why the application of model predictive control (MPC) to it is being investigated further.

Model predictive control is an advanced control technique that is used for difficult control problems $[34,35]$, and it has its primary advantage to be the explicit handling of constraints [34, 36]. MPC is an appropriately descriptive name for computer control schemes that utilize a process model for two explicit prediction of future behaviour and computation of appropriate corrective control action required to drive the predicted output as close as possible to the desired target value in an optimal manner. As an advanced control method, MPC has enjoyed such remarkable industrial success and popularity that, currently, it is the most widely utilized of all advanced control methodologies in industrial applications [34, 37-39].

Researches have applied various control techniques to reactive distillation processes. The summary of some of them is given in Table 1 .

Table 1. Some past studies carried on control of reactive distillation processes

\begin{tabular}{|c|c|c|c|}
\hline $\mathbf{S} / \mathbf{N}$ & Author(s) & Method & Product \\
\hline 1. & Wang and Wong [40] & PI Control & Isopropanol \\
\hline 2. & Barroso-Muñoz et al. [41] & PI Control & Ethyl acetate \\
\hline 3. & Kawathekar and Riggs [42] & Nonlinear MPC & Ethyl acetate \\
\hline 4. & Lai et al. [43] & PI Control & Ethyl and isopropyl acetates \\
\hline 5. & Venkateswarlu and Reddy [44] & Nonlinear MPC & Ethyl acetate \\
\hline 6. & Wang et al. [45] & PI Control & $\begin{array}{l}\text { Methanol and n-butyl } \\
\text { acetate }\end{array}$ \\
\hline 7. & Kumar and Kaistha [46] & PID Control & Methyl acetate \\
\hline 8. & Bahar and Özgen [47] & $\begin{array}{ll}\text { Neural } & \text { Network } \\
\text { Estimator } & \end{array}$ & Ethyl acetate \\
\hline 9. & Giwa and Karacan [48] & Decoupling PID Control & Ethyl acetate \\
\hline 10. & Giwa and Karacan [49] & Decoupling MPC & Ethyl acetate \\
\hline 11. & Giwa et al. [18] & PID Control & Biodiesel \\
\hline 12. & Giwa et al. [6] & PID Control & Biodiesel \\
\hline 13. & Giwa [50] & PID Control & Isopropyl alcohol \\
\hline
\end{tabular}

As can be seen from the literature review summarized in Table 1, none of the studies listed has applied model predictive control to a reactive distillation process producing biodiesel, which is a renewable energy. In order to bridge this gap, it is aimed in this work to carry out the control of the process for both set-point tracking and disturbance rejection by applying model predictive control.

\section{Methodology}

\section{Development of Closed-Loop Simulink Models of the Process}

The open-loop simulation of the process using Simulink has already been done by Giwa et al. [6]. As such, only the closed-loop simulation is focused on in this work.

The model predictive control of the reactive distillation process for the development of biodiesel (a renewable energy) was achieved by using the transfer function of the process obtained from the work of Giwa et al. [6] and given in Equation (1) to develop its Simulink models shown in Figure (1) and Figure (2) for servo (set-point tracking) and regulatory (disturbance rejection) control systems, respectively. The Simulink model was developed by picking and connecting appropriate blocks from the Simulink library of MATLAB [51].

$$
x_{\text {biod }}(s)=\frac{0.3382 \mathrm{e}^{(-8.999 \mathrm{~s})}}{248.43 \mathrm{~s}+1} Q(s)+\frac{0.283 \mathrm{e}^{(-1.993 \mathrm{~s})}}{151.87 \mathrm{~s}+1} R(s)
$$




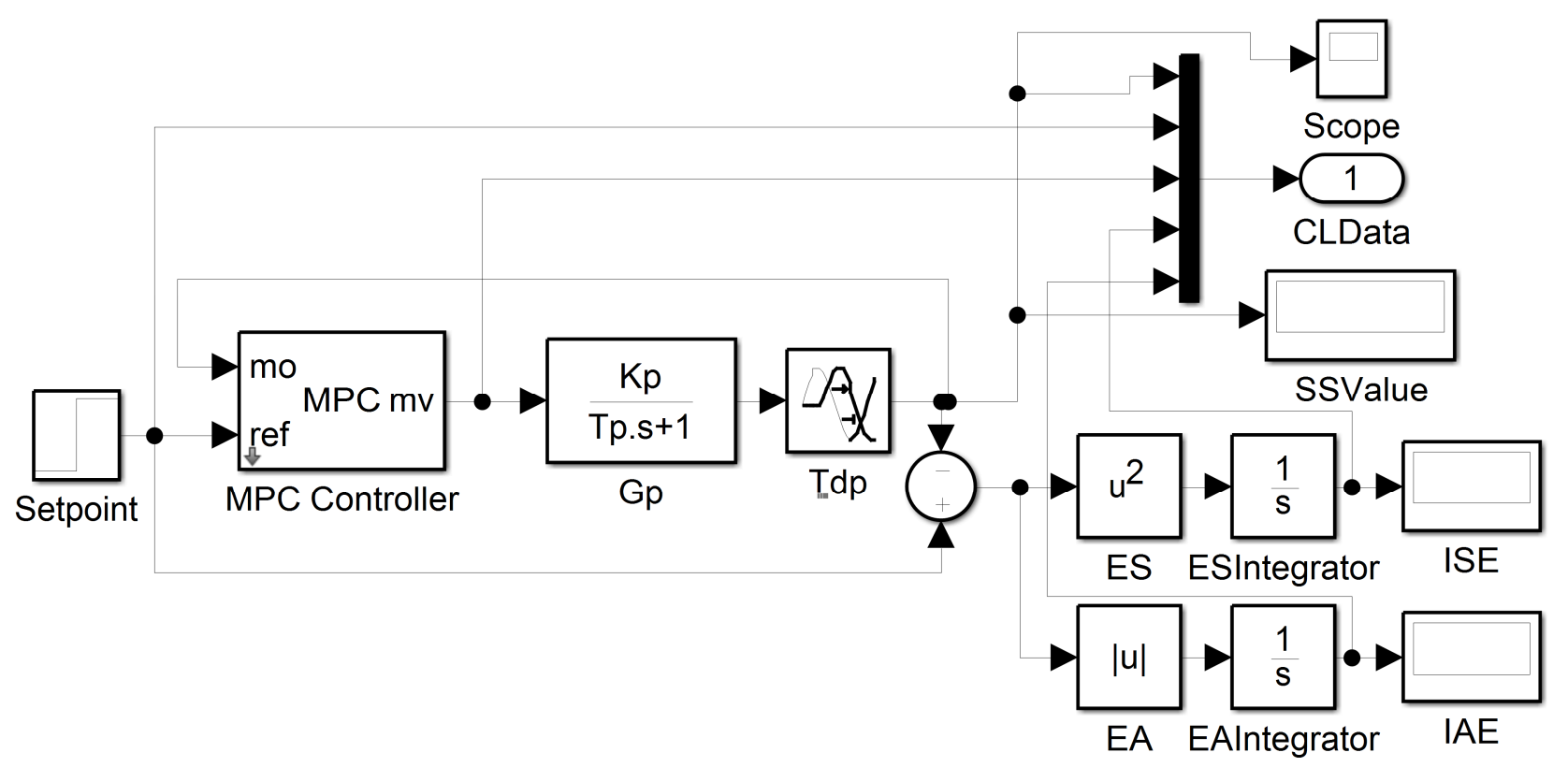

Figure 1. Simulink model of reactive distillation system for set-point tracking control

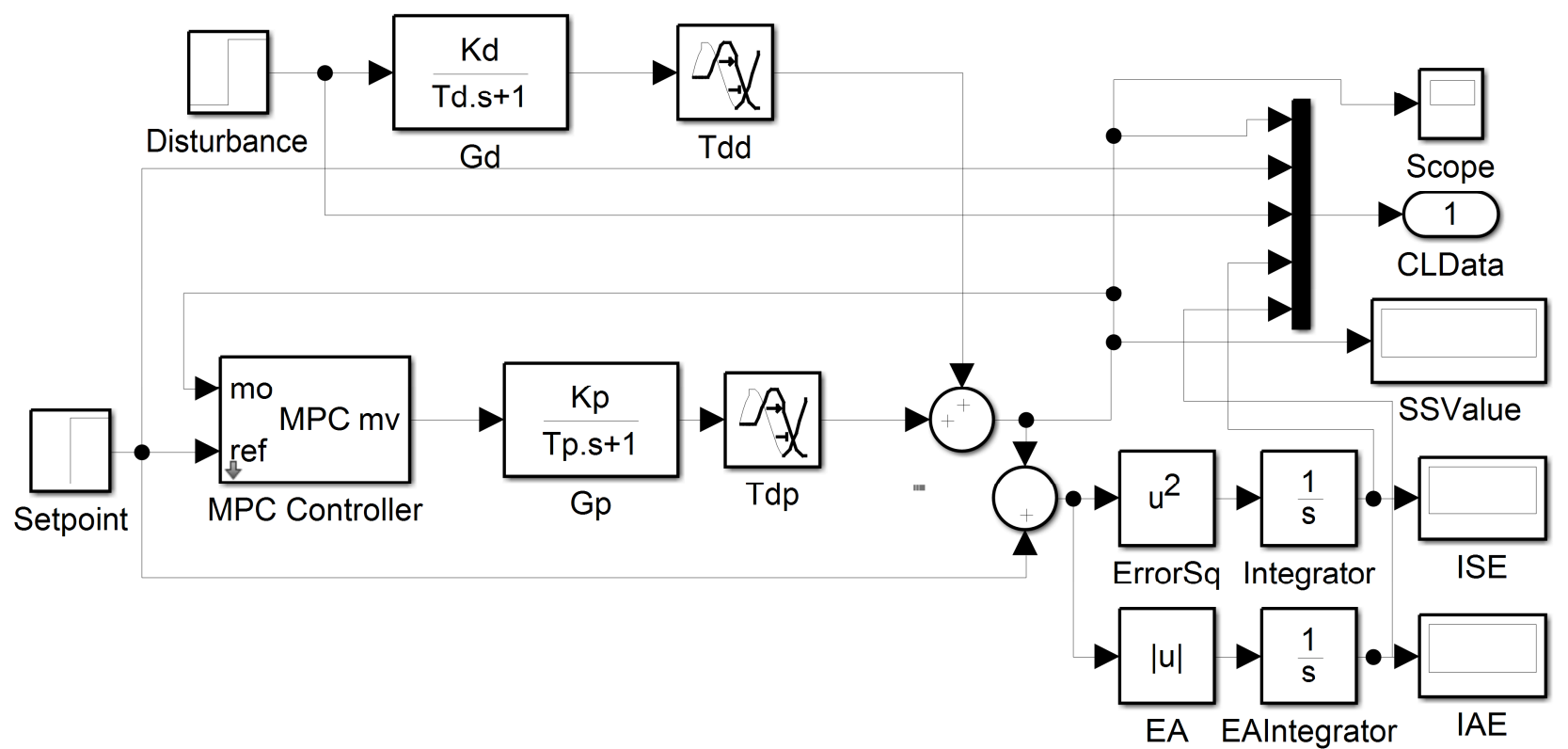

Figure 2. Simulink model of reactive distillation system for disturbance rejection control

In the simulation of the control systems, the controlled variable was the mole fraction ( $\left.\mathrm{x}_{\text {biod }}\right)$ obtained from the bottom section of the column, the manipulated variable was the reboiler duty (Q) and the disturbance variable was selected to be the reflux ratio (R).

\section{Estimation of Tuning Parameters}

The estimation of the tuning parameters of the controller was carried out by entering the low and the high bounds of each of the selected parameters (Table 2) into Design Expert [52], generating a set of thirty (30) runs given in Table 3 and using the values of the runs to simulate the closed-loop model of the main process coded in mfile of MATLAB. For each of the simulations executed, the integral absolute error (IAE) given as the output was recorded and, later, entered into the Design Expert for analysis and model equation development. 
Table 2. Range of control parameters used

\begin{tabular}{clccc}
\hline Factor & Name & Type & Low & High \\
\hline A & Prediction horizon & Numeric & 3 & 9 \\
B & Control horizon & Numeric & 9 & 21 \\
C & Manipulated variable rate weight & Numeric & 0 & 1.5 \\
D & Output variable weight & Numeric & 0 & 1.5 \\
\hline
\end{tabular}

Table 3. Designed tuning parameter values

\begin{tabular}{|c|c|c|c|c|}
\hline Run & Control horizon & Prediction horizon & $\mathbf{w}_{\text {urate }}$ & $\mathbf{w}_{\mathbf{y}}$ \\
\hline 1 & 9 & 9 & 0 & 1.5 \\
\hline 2 & 3 & 21 & 0 & 0 \\
\hline 3 & 9 & 21 & 1.5 & 1.5 \\
\hline 4 & 6 & 9 & 0.75 & 0.75 \\
\hline 5 & 9 & 9 & 1.5 & 1.5 \\
\hline 6 & 3 & 9 & 0 & 0 \\
\hline 7 & 6 & 15 & 0.75 & 0.75 \\
\hline 8 & 3 & 21 & 1.5 & 1.5 \\
\hline 9 & 9 & 15 & 0.75 & 0.75 \\
\hline 10 & 3 & 9 & 1.5 & 1.5 \\
\hline 11 & 3 & 9 & 0 & 1.5 \\
\hline 12 & 3 & 15 & 0.75 & 0.75 \\
\hline 13 & 6 & 15 & 0.75 & 1.5 \\
\hline 14 & 3 & 9 & 1.5 & 0 \\
\hline 15 & 9 & 21 & 1.5 & 0 \\
\hline 16 & 9 & 21 & 0 & 1.5 \\
\hline 17 & 6 & 15 & 0 & 0.75 \\
\hline 18 & 3 & 21 & 1.5 & 0 \\
\hline 19 & 6 & 15 & 0.75 & 0 \\
\hline 20 & 9 & 9 & 1.5 & 0 \\
\hline 21 & 6 & 15 & 0.75 & 0.75 \\
\hline 22 & 6 & 21 & 0.75 & 0.75 \\
\hline 23 & 6 & 15 & 0.75 & 0.75 \\
\hline 24 & 6 & 15 & 0.75 & 0.75 \\
\hline 25 & 3 & 21 & 0 & 1.5 \\
\hline 26 & 6 & 15 & 0.75 & 0.75 \\
\hline 27 & 9 & 21 & 0 & 0 \\
\hline 28 & 9 & 9 & 0 & 0 \\
\hline 29 & 6 & 15 & 1.5 & 0.75 \\
\hline 30 & 6 & 15 & 0.75 & 0.75 \\
\hline
\end{tabular}

The developed model equation relating the integral absolute error to the tuning parameters were analysed and modified appropriately in order to ensure that the contained parameters were significant enough to describe the phenomenon before proceeding to optimization.

\section{Estimation of Optimum Tuning Parameters}

The optimum control parameters used in the control of the process were estimated with the aid of Excel Solver [53] by setting the objective function, which was the integral absolute error (IAE) to be equal to zero and manipulating the four selected parameters (control horizon, prediction horizon, weight on manipulated variable rate and weight on output variable). The integral absolute 
error was chosen as the variable of the objective function in this work because it was discovered from the literature that it could eliminate small errors, and the elimination of small errors were found necessary in the production of biodiesel because mole fraction was being considered.

\section{Results and Discussion}

\section{Model Development Results}

The results of the integral absolute error (IAE) obtained when the developed control system was run using the values of the tuning parameters generated with the aid of Design Expert are given together the generated values in Table 4. According to the results given in Table 4, the values of the integral absolute error were discovered to be changing as the values of the tuning parameters were being varied. This was an indication that the tuning parameters were having effects on the developed control system of the reactive distillation process for renewable energy (biodiesel) production.

Table 4. Integral absolute error of the simulation with MPC tuning parameters

\begin{tabular}{|c|c|c|c|c|c|}
\hline Run & Control horizon & Prediction horizon & $\mathbf{W}_{\text {urate }}$ & $\mathbf{w}_{\mathbf{y}}$ & IAE \\
\hline 1 & 9 & 9 & 0 & 1.5 & 162.13 \\
\hline 2 & 3 & 21 & 0 & 0 & 2750.00 \\
\hline 3 & 9 & 21 & 1.5 & 1.5 & 134.67 \\
\hline 4 & 6 & 9 & 0.75 & 0.75 & 2746.83 \\
\hline 5 & 9 & 9 & 1.5 & 1.5 & 2746.83 \\
\hline 6 & 3 & 9 & 0 & 0 & 2750.00 \\
\hline 7 & 6 & 15 & 0.75 & 0.75 & 178.79 \\
\hline 8 & 3 & 21 & 1.5 & 1.5 & 134.63 \\
\hline 9 & 9 & 15 & 0.75 & 0.75 & 178.79 \\
\hline 10 & 3 & 9 & 1.5 & 1.5 & 2746.83 \\
\hline 11 & 3 & 9 & 0 & 1.5 & 162.13 \\
\hline 12 & 3 & 15 & 0.75 & 0.75 & 178.79 \\
\hline 13 & 6 & 15 & 0.75 & 1.5 & 146.39 \\
\hline 14 & 3 & 9 & 1.5 & 0 & 2750.00 \\
\hline 15 & 9 & 21 & 1.5 & 0 & 2750.00 \\
\hline 16 & 9 & 21 & 0 & 1.5 & 5.00 \\
\hline 17 & 6 & 15 & 0 & 0.75 & 5.00 \\
\hline 18 & 3 & 21 & 1.5 & 0 & 2750.00 \\
\hline 19 & 6 & 15 & 0.75 & 0 & 2750.00 \\
\hline 20 & 9 & 9 & 1.5 & 0 & 2750.00 \\
\hline 21 & 6 & 15 & 0.75 & 0.75 & 178.79 \\
\hline 22 & 6 & 21 & 0.75 & 0.75 & 134.66 \\
\hline 23 & 6 & 15 & 0.75 & 0.75 & 178.79 \\
\hline 24 & 6 & 15 & 0.75 & 0.75 & 178.79 \\
\hline 25 & 3 & 21 & 0 & 1.5 & 5.00 \\
\hline 26 & 6 & 15 & 0.75 & 0.75 & 178.79 \\
\hline 27 & 9 & 21 & 0 & 0 & 2750.00 \\
\hline 28 & 9 & 9 & 0 & 0 & 2750.00 \\
\hline 29 & 6 & 15 & 1.5 & 0.75 & 262.92 \\
\hline 30 & 6 & 15 & 0.75 & 0.75 & 178.79 \\
\hline
\end{tabular}


Analysing the obtained results given in Table 4, a model (Equation (2)) was developed for the relationship existing between the integral absolute error and the tuning parameters selected, which were the control horizon, the prediction horizon, the weight on the manipulated variable rate and the weight on the output variable.

$$
\begin{aligned}
I A E=6842.65+340.30 \mathrm{~A}-805.57 \mathrm{~B}+1791.92 \mathrm{C}-3373.84 \mathrm{D}+\cdots \\
\quad \cdots+1.42 \times 10^{-4} \mathrm{AB}+1.13 \times 10^{-3} \mathrm{AC}+1.13 \times 10^{-3} \mathrm{AD}-68.20 \mathrm{BC}+\cdots \\
\quad \cdots+-76.93 \mathrm{BD}+603.19 \mathrm{CD}-28.36 \mathrm{~A}^{2}+27.96 \mathrm{~B}^{2}-533.43 \mathrm{C}^{2}+1802.99 \mathrm{D}^{2}
\end{aligned}
$$

After developing the model given in Equation (2), it was analysed for variance, and Table 5 shows the results of the analysis. From the table, it was found that some of the factors contained in the model were insignificant because their p-values were greater than 0.05 that was chosen based on 95\% confidence level. Besides, observing Equation (2) very well, the coefficients of some of those factors having p-values to be greater than 0.05 were found to be very low. Based on this, the developed model equation was subjected to modification.

Table 5. ANOVA outputs of the developed model

\begin{tabular}{lcccccc}
\hline Source & Sum of squares & df & Mean square & F value & p-value & \\
\hline Model & $4.53 \mathrm{E}+07$ & 14 & $3.24 \mathrm{E}+06$ & 13.41 & $<0.0001$ & significant \\
A-A & 0 & 1 & 0 & 0 & 1 & \\
B-B & $3.69 \mathrm{E}+06$ & 1 & $3.69 \mathrm{E}+06$ & 15.28 & 0.0014 & \\
C-C & $1.80 \mathrm{E}+06$ & 1 & $1.80 \mathrm{E}+06$ & 7.44 & 0.0156 & \\
D-D & $1.90 \mathrm{E}+07$ & 1 & $1.90 \mathrm{E}+07$ & 78.75 & $<0.0001$ & \\
$\mathrm{AB}$ & 0 & 1 & 0 & 0 & 1 & \\
$\mathrm{AC}$ & 0 & 1 & 0 & 0 & 1 & \\
$\mathrm{AD}$ & 0 & 1 & 0 & 0 & 1 & \\
$\mathrm{BC}$ & $1.51 \mathrm{E}+06$ & 1 & $1.51 \mathrm{E}+06$ & 6.24 & 0.0246 & \\
$\mathrm{BD}$ & $1.92 \mathrm{E}+06$ & 1 & $1.92 \mathrm{E}+06$ & 7.94 & 0.013 & \\
CD & $1.84 \mathrm{E}+06$ & 1 & $1.84 \mathrm{E}+06$ & 7.62 & 0.0146 & \\
$\mathrm{~A}^{2}$ & $1.69 \mathrm{E}+05$ & 1 & $1.69 \mathrm{E}+05$ & 0.7 & 0.4164 & \\
$\mathrm{~B}^{2}$ & $2.63 \mathrm{E}+06$ & 1 & $2.63 \mathrm{E}+06$ & 10.87 & 0.0049 & \\
$\mathrm{C}^{2}$ & $2.33 \mathrm{E}+05$ & 1 & $2.33 \mathrm{E}+05$ & 0.97 & 0.3414 & \\
$\mathrm{D}^{2}$ & $2.67 \mathrm{E}+06$ & 1 & $2.67 \mathrm{E}+06$ & 11.03 & 0.0047 & \\
Residual & $3.62 \mathrm{E}+06$ & 15 & $2.42 \mathrm{E}+05$ & & & \\
Lack of Fit & $3.62 \mathrm{E}+06$ & 10 & $3.62 \mathrm{E}+05$ & & \\
Pure Error & 0 & 5 & 0 & & \\
Cor Total & $4.90 \mathrm{E}+07$ & 29 & & & & \\
\hline
\end{tabular}

Equation (3) shows the modified model of the relationship between the integral absolute error and the selected tuning parameters of the model predictive control system. Even though the pvalue of factor A (control horizon) was greater than 0.05 , it was still not eliminated from the model because the control system must have a control horizon as one of the tuning parameters.

$$
\begin{array}{r}
I A E=6421.61+7.67 \times 10^{-4} \mathrm{~A}-611.52 \mathrm{~B}+991.78 \mathrm{C}-2752.87 \mathrm{D}-68.20 \mathrm{BC}+\cdots \\
\cdots+-76.93 \mathrm{BD}+603.19 \mathrm{C} \mathrm{D}+21.50 \mathrm{~B}^{2}+1389.01 \mathrm{D}^{2}
\end{array}
$$


Table 6. ANOVA outputs of the modified model

\begin{tabular}{lcccccc}
\hline Source & Sum of squares & df & Mean square & F value & p-value & \\
\hline Model & $4.48 \mathrm{E}+07$ & 9 & $4.98 \mathrm{E}+06$ & 23.73 & $<0.0001$ & significant \\
A-A & 0 & 1 & 0 & 0 & 1 & \\
B-B & $3.69 \mathrm{E}+06$ & 1 & $3.69 \mathrm{E}+06$ & 17.6 & 0.0004 & \\
C-C & $1.80 \mathrm{E}+06$ & 1 & $1.80 \mathrm{E}+06$ & 8.57 & 0.0083 & \\
D-D & $1.90 \mathrm{E}+07$ & 1 & $1.90 \mathrm{E}+07$ & 90.75 & $<0.0001$ & \\
BC & $1.51 \mathrm{E}+06$ & 1 & $1.51 \mathrm{E}+06$ & 7.19 & 0.0144 & \\
BD & $1.92 \mathrm{E}+06$ & 1 & $1.92 \mathrm{E}+06$ & 9.14 & 0.0067 & \\
CD & $1.84 \mathrm{E}+06$ & 1 & $1.84 \mathrm{E}+06$ & 8.79 & 0.0077 & \\
$B^{2}$ & $2.06 \mathrm{E}+06$ & 1 & $2.06 \mathrm{E}+06$ & 9.84 & 0.0052 & \\
$D^{2}$ & $2.10 \mathrm{E}+06$ & 1 & $2.10 \mathrm{E}+06$ & 10.03 & 0.0048 & \\
Residual & $4.19 \mathrm{E}+06$ & 20 & $2.10 \mathrm{E}+05$ & & & \\
Lack of Fit & $4.19 \mathrm{E}+06$ & 15 & $2.80 \mathrm{E}+05$ & & & \\
Pure Error & 0 & 5 & 0 & & & \\
Cor Total & $4.90 \mathrm{E}+07$ & 29 & & & & \\
\hline
\end{tabular}

The analysis of variance (ANOVA), the results of which is given in Table 6, carried out on the modified model showed each of the factors to have a p-value that was less than 0.05 except that of the factor A, which was not eliminated deliberately so as to have a control horizon as a tuning parameter in the control system. After the modification of the model, an improvement in the predicted R-Squared value of the model was noticed to occur because the predicted R-Squared for the original developed model was 0.5568 while that of the modified one has been estimated to be 0.7612 .

\section{Optimum Parameters}

After modifying the model of the relationship between IAE and the tuning parameters, Equation (3) was optimized with the aid of Excel Solver, and the results of the optimization obtained are given in Table 7.

Table 7. Estimated optimum control parameters

\begin{tabular}{lc}
\hline Parameter & Value \\
\hline Control horizon & 11 \\
Prediction horizon & 18 \\
Weight on manipulated variable rate & 0.05 \\
Weight on output variable & 2.17 \\
Absolute value of objective function (IAE) & 0.00167 \\
\hline
\end{tabular}

From the results of the optimization given in Table 7, it was observed that, although the set value of the objective function, which was zero, could not be satisfied, the value obtained was found reasonable enough because the control system was expected to be able to handle any mismatch that could occur as a result of that.

\section{Servo (Set-Point Tracking) Control Simulation Responses}

In order to demonstrate the application of model predictive control to renewable energy development, the values of the tuning parameters were set to those ones obtained from the optimization carried out and given in Table 7, then the closed-loop control system of the reactive distillation process was simulated for set-point tracking by applying step changes to the value of the mole fraction of biodiesel obtained from the bottom section of the column, which was the controlled variable of the system, and the results obtained were as given in Figures $3-5$. 
Shown in Figure 3 is the closed-loop response of the system when a step change of 0.4 was applied to the set point of the controlled variable. As can be seen from the figure showing the controlled and the manipulated variables, the mole fraction of biodiesel was able to get settled at the desired reference value within a simulation time of $60 \mathrm{~min}$. The results obtained revealed that model predictive control was able to make the system behave well within a short time of $1 \mathrm{hr}$ with very few oscillations. In this case, the integral absolute error (IAE) and integral squared error (ISE) of the simulation were obtained to be approximately 6.05 and 2.05 , respectively.
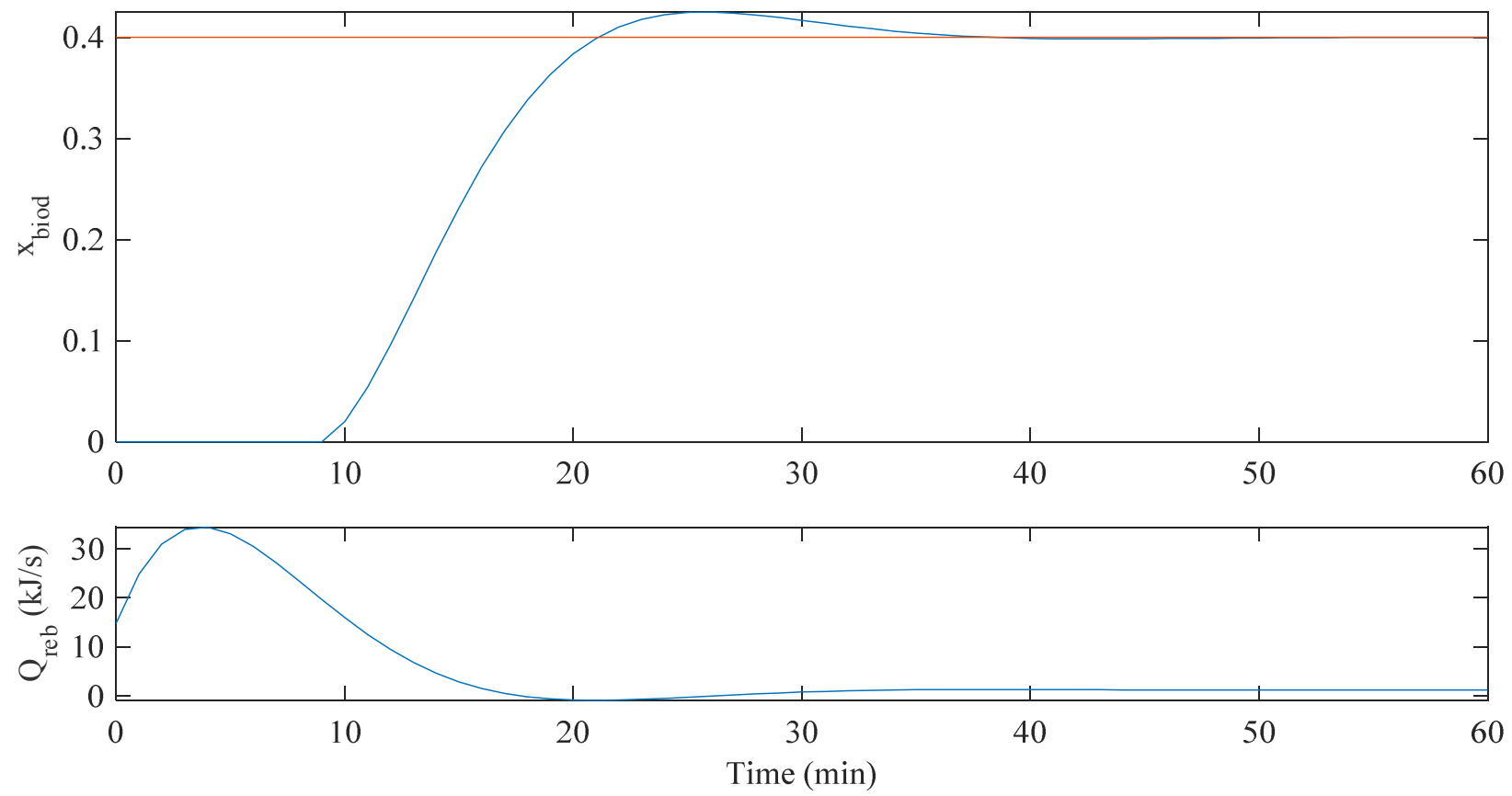

Figure 3. Closed-loop dynamic response of the system to a 0.4-unit step change in the set-point of biodiesel mole fraction

The response (Figure 4) given by the system for a 0.5 -unit step change was also found to be similar to the one obtained before (in the case of a 0.4-unit step change) because the system was also able to get to its mole fraction of 0.5 within a simulation time of $1 \mathrm{hr}$. However, an increase was found to occur in each of IAE and ISE because the values of IAE and ISE obtained in this simulation were 7.57 and 3.20 respectively. The increase in the values of the IAE and ISE was found to be as a result of the increase in the value of the step applied to the set-point of the controlled variable. 

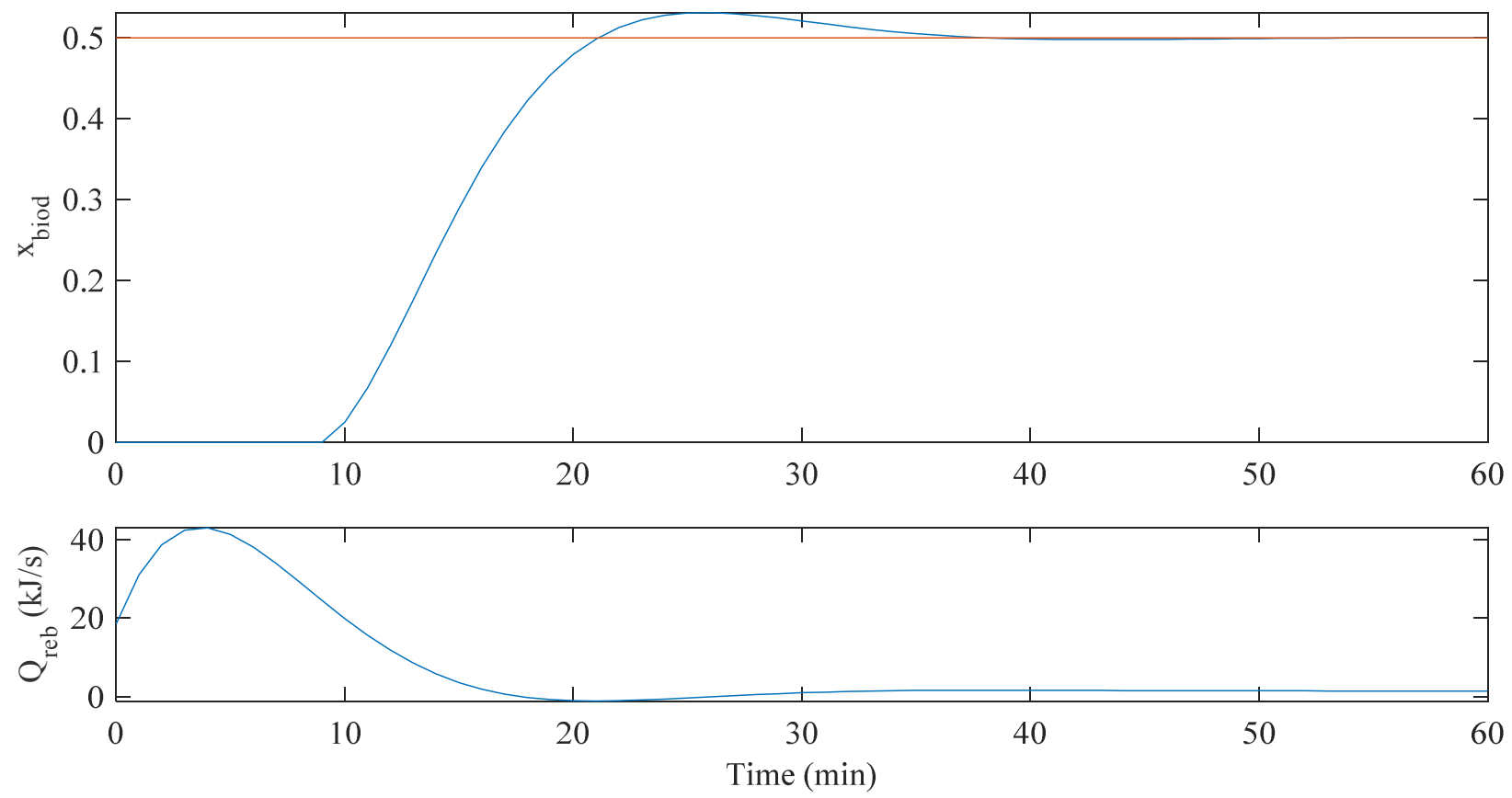

Figure 4. Closed-loop dynamic response of the system to a 0.5 -unit step change in the set-point of biodiesel mole fraction
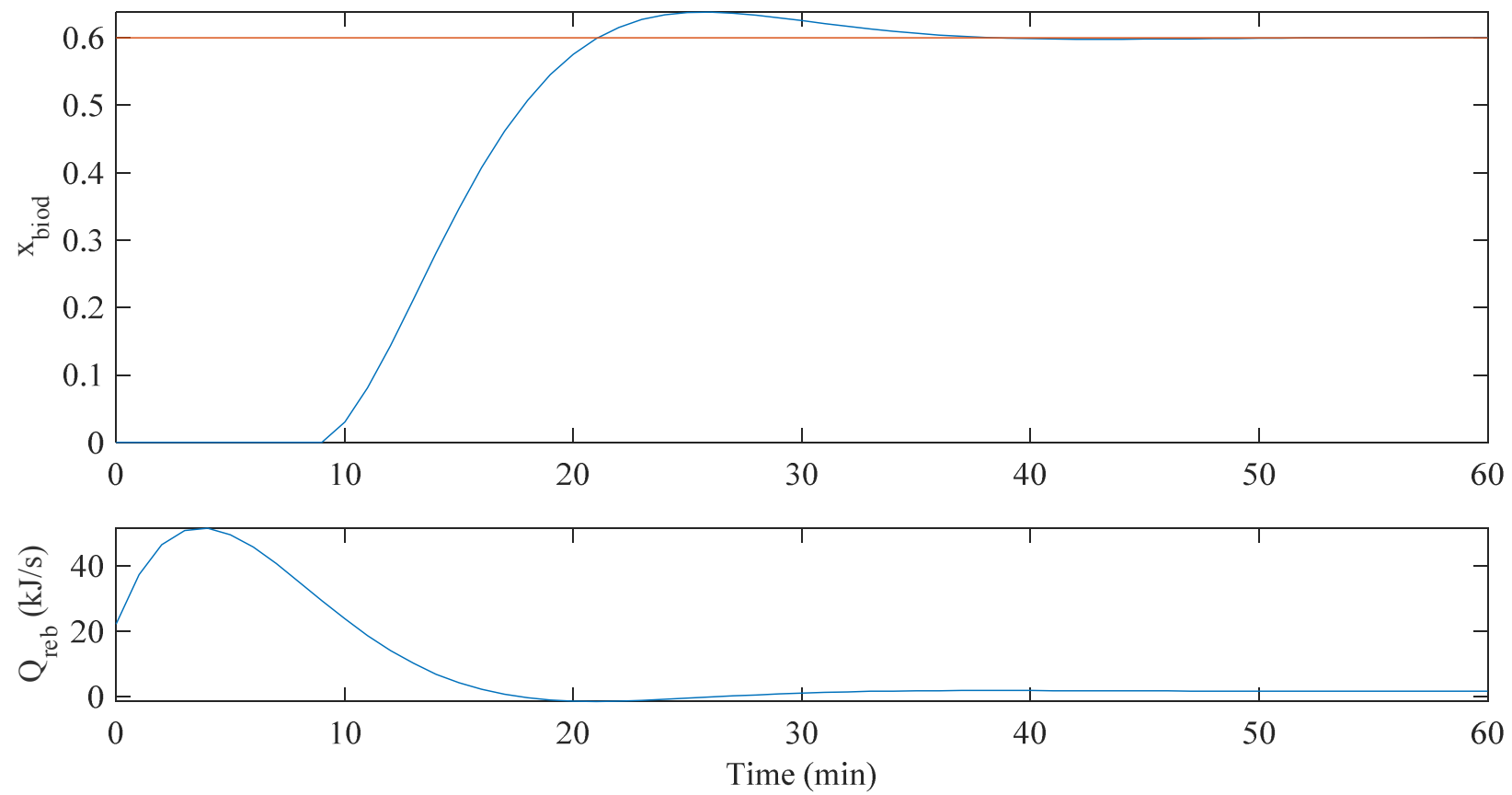

Figure 5. Closed-loop dynamic response of the system to a 0.6-unit step change in the set-point of biodiesel mole fraction

Figure 5 shows the closed-loop dynamic response of the reactive distillation process used for renewable energy development to a step change of 0.6 unit in the value of the controlled variable. The observation made from the figure pointed out that the response of the system in this case too was similar to the ones obtained before as the system has been found to get to its closedloop steady-state value of 0.6 within $60 \mathrm{~min}$ simulation time considered and with respective IAE and ISE values of 9.08 and 4.61 . 


\section{Regulatory (Disturbance Rejection) Control Simulation Responses}

In addition to the application of model predictive control to renewable energy development carried out in this work for servo simulation, the ability of the control system in the presence of a disturbance was also investigated using the same tuning parameters that were used for servo control simulations. The results of the simulations carried out with disturbance rejection control of the reactive distillation process were as shown in Figures 6-8 respectively for a $0.5-, 1-$ and 1.5-unit step changes in the reflux ratio, which was selected as the disturbance variable of the process.

From Figure 6 that is showing the closed-loop dynamic response of the regulatory control of the reactive distillation process, it was observed that the system was able to return to its steadystate, but after a long time of about $800 \mathrm{~min}$. This too much settling time for the regulatory control simulation was seen to be as a result of the fact that the tuning parameters were not working very well for the disturbance rejection control the way they did for the set-point tracking control system, although the IAE and ISE of the control simulation were finally obtained to be 2.13 and 0.015 respectively.
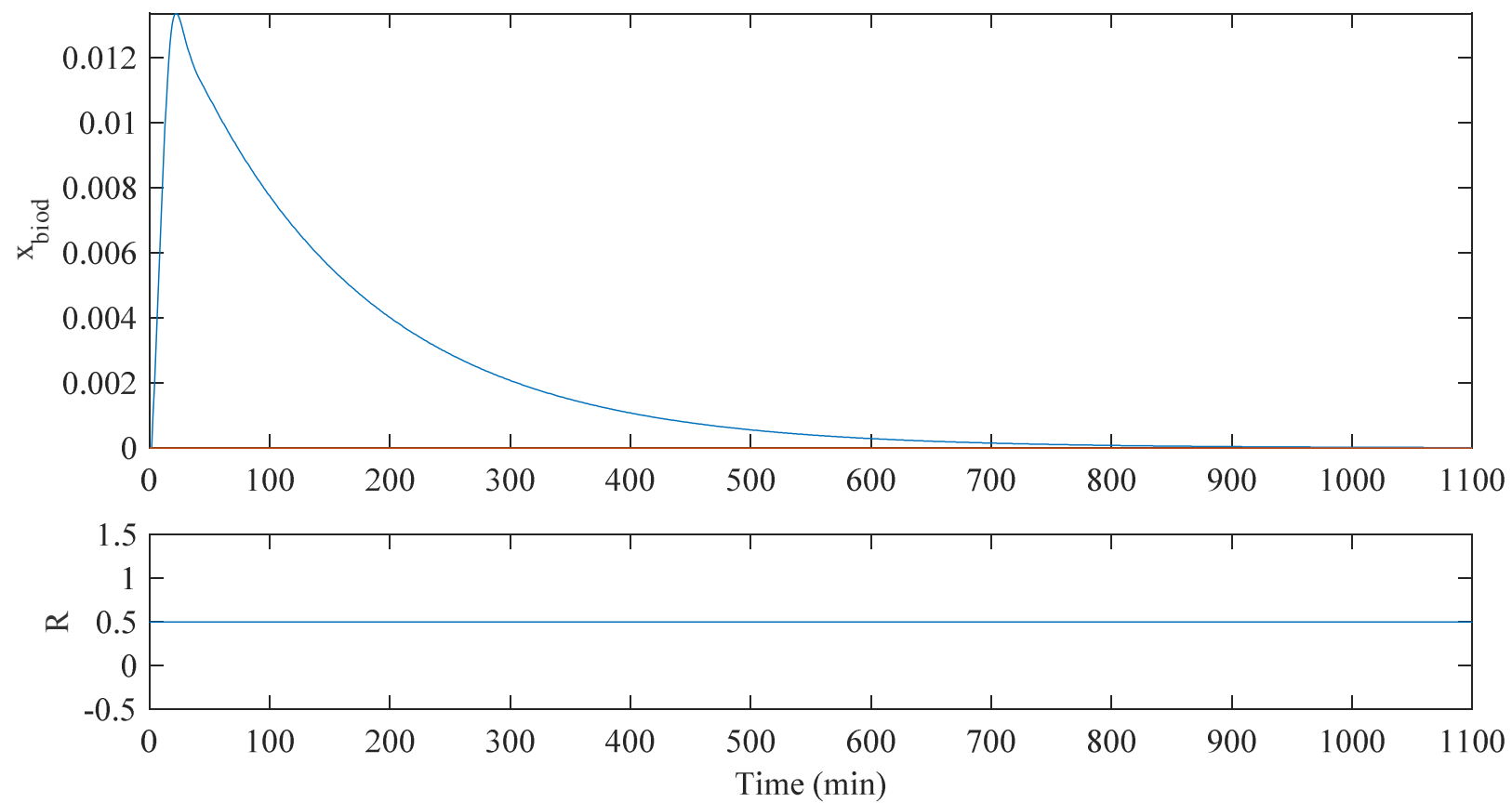

Figure 6. Closed-loop dynamic response of the system to a 0.5 -unit step change in the disturbance variable

Figure 7 shows the response of the model predictive controlled reactive distillation system to a unit step change in the disturbance variable. The trend of the response given in this case was found not to be too different from that given in Figure 6 for a step change of 0.5 unit in the disturbance variable. Just as it was observed in the other case, the settling time in this case also was found to be too much. For this simulation, the IAE and ISE were estimated to be 4.27 and 0.058 respectively. 

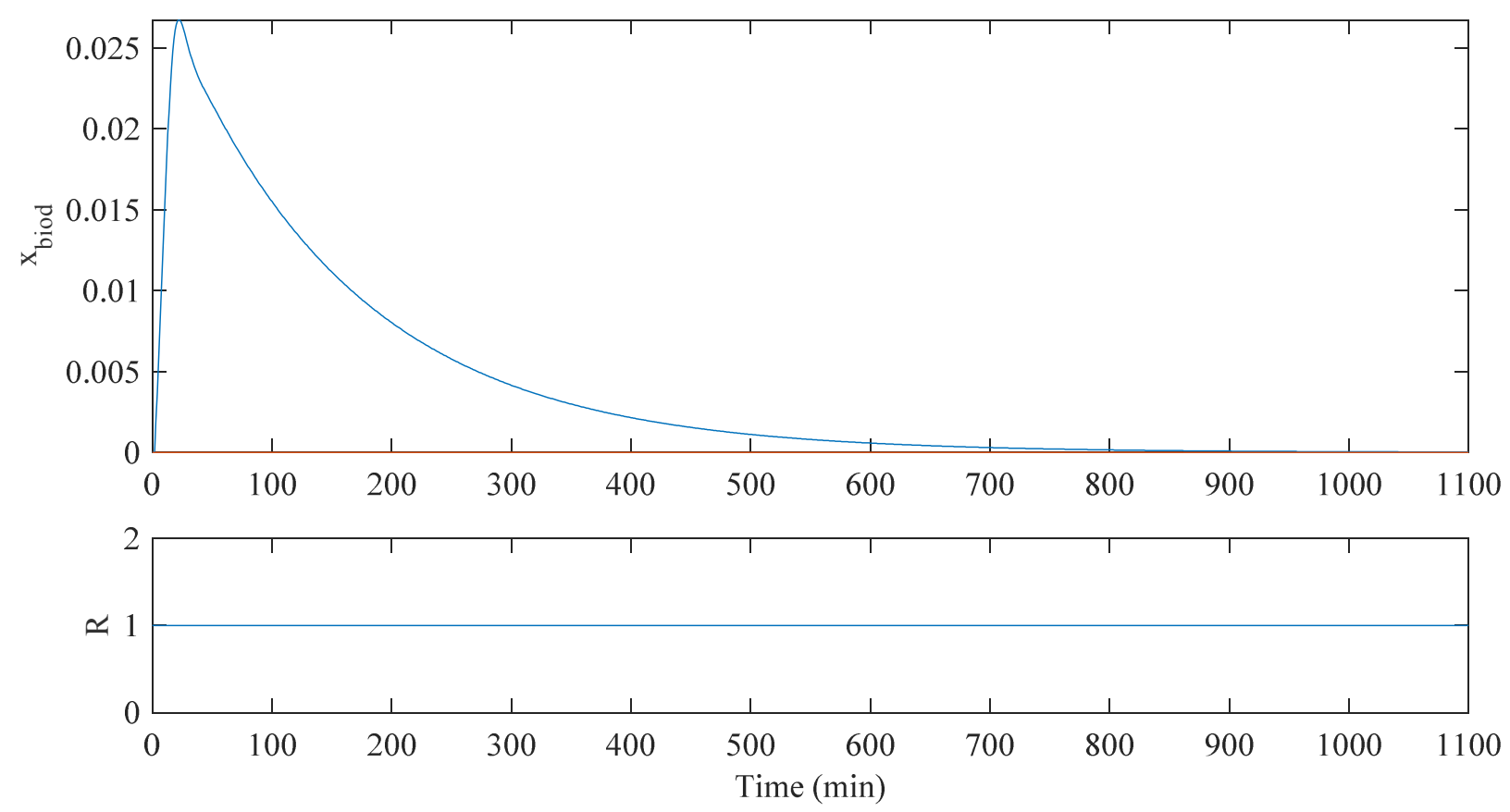

Figure 7. Closed-loop dynamic response of the system to a 1-unit step change in the disturbance variable
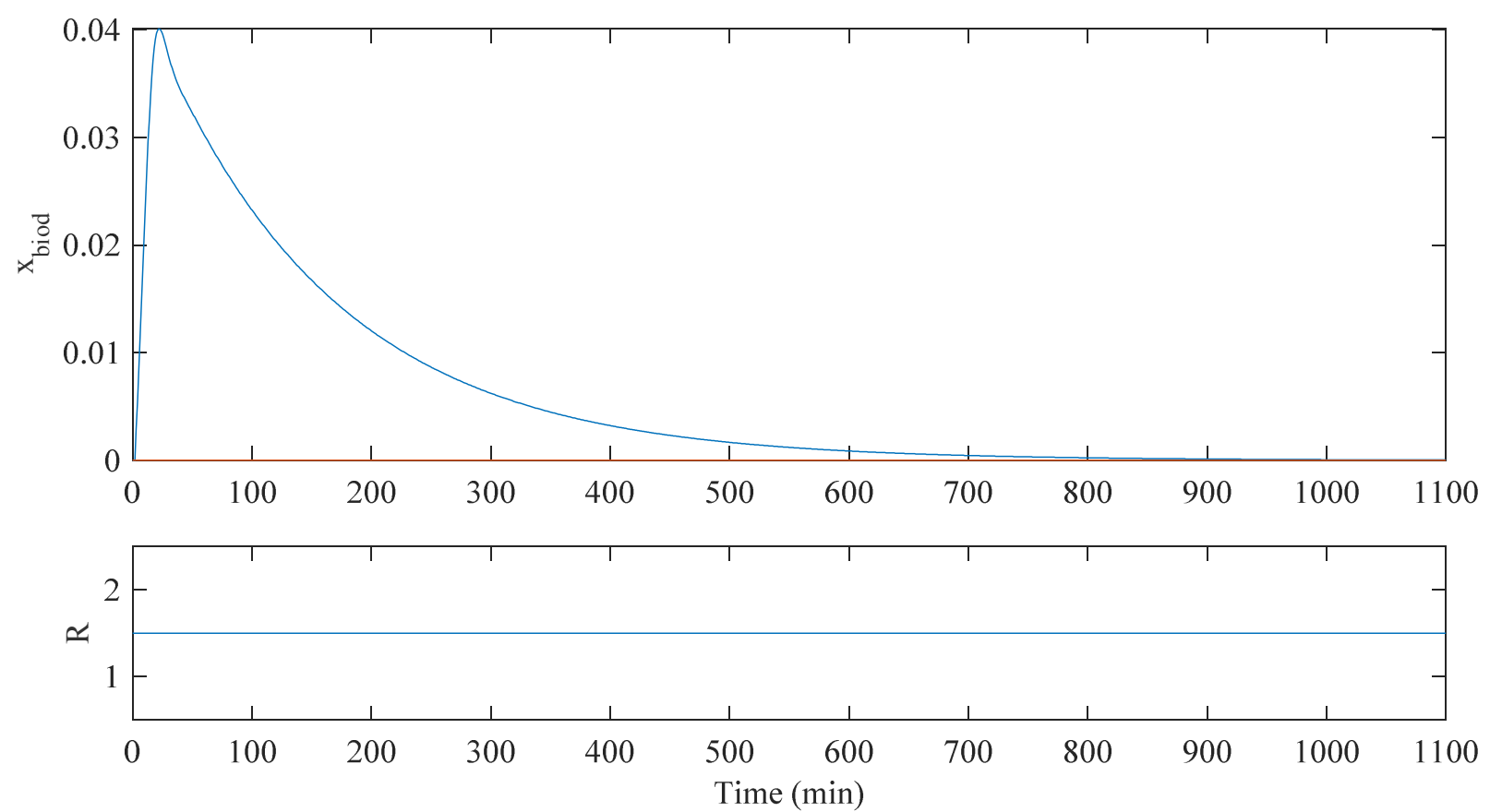

Figure 8. Closed-loop dynamic response of the system to a 1.5-unit step change in the disturbance variable

The observation made from Figure 8 showing the dynamic response of the reactive distillation system when it was simulated with a model predictive controller upon the application of 1.5-unit step change to the reflux ratio (disturbance variable) was similar to the ones obtained from the immediate past two figures (Figures 6 and 7) in the sense that the system was only able to return to its steady state at about $800 \mathrm{~min}$. The values of IAE and ISE estimated from this simulation involving 1.5-unit step change in the disturbance variable revealed that the higher the step applied the higher the integral absolute error and the integral squared error because the values of IAE and ISE were obtained in this case to be 6.4 and 0.13 respectively. 
Comparing the results obtained from servo simulations, the model predictive controller (MPC) used in this work was found to perform better than the proportional-integral-derivative (PID) used in the work of Giwa et al. [18] because the settling time and the oscillations exhibited by the model predictive controller were less than those of the PID controller. However, the settling time of the process when PID controller was used in the work of Giwa et al. [6] to carry out its regulatory control simulation was found to be better than the one given by the model predictive controller in this work, but the number of oscillations recorded in this work was found to be less than that of the work of Giwa et al. [6].

\section{Conclusion}

The analysis of the results obtained from the simulations carried out for the optimization of the tuning parameters revealed that integral absolute error of the model predictive control system was less affected by the control horizon, among the tuning parameters considered, because its $\mathrm{p}$ value was greater than 0.05 based on $95 \%$ confidence level. Furthermore, the simulation of the closed-loop system of reactive distillation process for biodiesel production using model predictive control tuned with the optimum parameters (control horizon of 11, prediction horizon of 18, weight on manipulated variable rate of 0.05 and weight on output variable of 2.17) obtained showed that the system was well handled by the controller used under set-point tracking because it was able to get settled at the desired mole fraction within $60 \mathrm{~min}$. However, the settling time recorded in the case of disturbance rejection control system of the process with the same controller was found not to be encouraging. It is, therefore, recommended that further work should be carried out in order to obtain tuning parameters that will reduce the settling time of the closed-loop system of the process under regulatory control simulation also.

\section{Acknowledgement}

Special thanks go to Aare Afe Babalola and the Management of Afe Babalola University, Ado-Ekiti, Ekiti State, Nigeria for providing a very conducive environment that enabled the accomplishment of this research work. Also, the encouragement as well as the support received from Abubakar Tafawa Balewa University, Bauchi, Nigeria is highly acknowledged and appreciated.

\section{References}

[1] T.A. Kuku, Case for Sustainable Green Energy Development. The Nigeria Photovoltaic Energy Conference (SOLARCON 2014).

[2] O. Ellabban, H. Abu-Rub, and F. Blaabjerg, Renewable energy resources: current status, future prospects and their enabling technology. Renewable and Sustainable Energy Reviews, 39 (2014) 748-764.

[3] L. Simasatitkul, P. Siricharnsakunchai, Y. Patcharavorachot, S. Assabumrungrat, and A. Arpornwichanop, Reactive distillation for biodiesel production from soybean oil, Korean J. Chem. Eng., 28(3) (2011) 649-655.

[4] A. Giwa, A. Bello, and S.O. Giwa, Performance analyses of fatty acids in reactive distillation process for biodiesel production, International Journal of Scientific \& Engineering Research, 5(12) (2014) 529-540.

[5] A. Giwa, A. Bello, and S.O. Giwa, Artificial neural network modeling of a reactive distillation process for biodiesel production, International Journal of Scientific \& Engineering Research, 6(1) (2015) 1175- 1191.

[6] S.O. Giwa, A.A. Adeyi, and A. Giwa, Dynamics and regulatory control of biodiesel purity from a reactive distillation process, International Journal of Engineering Research and General Science, 3(5) (2015) 371-381. 
[7] A. Giwa, and S.O. Giwa, Dynamics and Tyreus-Luyben tuned control of a fatty acid methyl ester reactive distillation process, International Journal of Engineering Research and General Science, 3(5) (2015) 799-808.

[8] F. Ahmed, S.O. Giwa, M. Ibrahim, and A. Giwa, Production of biodiesel from Jatropha curcas seed oil using base catalysed transesterification, International Journal of ChemTech Research, 9(6) (2016) 322-332.

[9] S.M. Akaagerger, S.O. Giwa, M. Ibrahim, and A. Giwa, Production of biodiesel from desert date seed oil, International Journal of ChemTech Research, 9(6) (2016) 453-463.

[10] C.S. Aalam, and C.G. Saravanan, Biodiesel production from mahua oil via catalytic transesterification method, International Journal of ChemTech Research, 8(4) (2015) 17061709.

[11] M.J. Selvakumar, S.J. Alexis, and K.S. Raj, Emission characteristics of a ci engine with the addition of different additives, International Journal of ChemTech Research, 8(4) (2015) 2064-2071.

[12] A. Giwa, and S.O. Giwa, Studying the dynamics of a fame reactive distillation system towards some input types, International Journal of ChemTech Research, 9(7) (2016) 466-476.

[13] K. Rajagopal, J. Johnson, and R.J. Selwin, Production of biodiesel from waste used cooking oil using two different alkaline catalysts, International Journal of ChemTech Research, 8(2) (2015) 754-759.

[14] V. Hariram, and R. Bharathwaaj, Extraction and optimization of biodiesel yield from wax esters of Apis melifera (honey bee), International Journal of ChemTech Research, 8(9) (2015) 433-437.

[15] K. Rajagopal, G.J. Newton, J.S. Rajadurai, C. Adhikesavan, and J. Johnson, Effect of temperature on the physical properties of sunflower biodiesel and their mixtures with palm biodiesel and petro diesel fuel, International Journal of ChemTech Research, 8(8) (2015) 371383.

[16] E.D. Daryono, In Situ Transesterification of Mahogany seed oil (Swietenia macrophylla king) become of methyl ester with co-solvent n-hexane, International Journal of ChemTech Research, 8(3) (2015) 1026-1031.

[17] C.A. Jimmy, Microwave assisted to biodiesel production from palm oil in time and material feeding frequency, International Journal of ChemTech Research, 8(4) (2015) 1695-1700.

[18] A. Giwa, S.O. Giwa, and A.A. Adeyi, Dynamics and servo control of biodiesel purity from a reactive distillation process, International Journal of Scientific \& Engineering Research, 6(8) (2015) 146-156.

[19] A. Giwa, Steady-state modeling of n-butyl acetate transesterification process using Aspen Plus: conventional versus integrated, ARPN Journal of Engineering and Applied Sciences, 7(12) (2012) 1555-1564.

[20] A. Giwa, Methyl acetate reactive distillation process modeling, simulation and optimization using Aspen Plus, ARPN Journal of Engineering and Applied Sciences, 8(5) (2013) 386-392.

[21] S.O. Giwa, A. Giwa, and H. Hapoglu, Investigating the effects of some parameters on hydrogen sulphide stripping column using Aspen HYSYS, ARPN Journal of Engineering and Applied Sciences, 8(5) (2013) 338-347.

[22] A. Giwa, S.O. Giwa, and H. Hapoglu, Adaptive Neuro-Fuzzy Inference Systems (ANFIS) modeling of reactive distillation process, ARPN Journal of Engineering and Applied Sciences, 8(7) (2013) 473-479.

[23] A. Giwa, and S. Karacan, Simulation and optimization of ethyl acetate reactive packed distillation process using Aspen Hysys, The Online Journal of Science and Technology, 2(2) (2012) 57-63.

[24] A. Giwa, and S. Karacan, Nonlinear black-box modeling of a reactive distillation process, International Journal of Engineering Research \& Technology, 1(7) (2012) 548-557. 
[25] A. Giwa, and S. Karacan, Decoupling Control of a reactive distillation process using TyreusLuyben technique, ARPN Journal of Engineering and Applied Sciences, 7(10) (2012) 12631272.

[26] A. Giwa, and S.O. Giwa, Isopropyl myristate production process optimization using response surface methodology and MATLAB, International Journal of Engineering Research \& Technology, 2(1) (2013) 853-862.

[27] A. Giwa, and S.O. Giwa, Estimating the optimum operating parameters of olefin metathesis reactive distillation process, ARPN Journal of Engineering and Applied Sciences, 8(8) (2013) 614-624.

[28] A. Giwa, S.O. Giwa, I. Bayram, and S. Karacan, Simulations and economic analyses of ethyl acetate productions by conventional and reactive distillation processes using Aspen Plus, International Journal of Engineering Research \& Technology, 2(8) (2013) 594-605.

[29] A. Giwa, Solving the dynamic models of reactive packed distillation process using difference formula approaches, ARPN Journal of Engineering and Applied Sciences, 9(2) (2014) 98108.

[30] A. Giwa, and S.O. Giwa, Modelling and simulation of a reactive distillation process for fuel additive production, Journal of Environmental Science, Computer Science and Engineering \& Technology, Section C: Engineering \& Technology, 5(1) (2016) 63-74.

[31] A. Giwa, and S. Karacan, Modeling and simulation of a reactive packed distillation column using delayed neural networks, Chaotic Modeling and Simulation, 2(1) (2012) 101-108.

[32] A. Giwa, and S.O. Giwa, Layer-recurrent neural network modelling of reactive distillation process, Chaotic Modeling and Simulation, 2(4) (2013) 647-656.

[33] A. Giwa, and S. Karacan, Development of dynamic models for a reactive packed distillation column, International Journal of Engineering, 6(3) (2012) 118-128.

[34] A. Giwa, Decoupling Neural Network Model Predictive Control: Algorithm Development and Application to Reactive Distillation Process, Lambert Academic Publishing, Germany, 2013.

[35] D.E. Seborg, T.F. Edgar, and D.A. Mellichamp, Process Dynamics and Control, 2nd Edition, Wiley, New Jersey, 2004.

[36] B.W. Bequette, Process Control: Modeling, Design, and Simulation, Prentice Hall, New Jersey, 2003.

[37] B.A. Ogunnaike, and W.H. Ray Process Dynamics, Modeling, and Control, Oxford University Press, New York, 1994.

[38] C.E. Garcia, D.M. Prett, and M. Morari, Model predictive control: theory and practice - A Survey, Automatica, 25 (1989) 335-348.

[39] S. Yamamoto, and I. Hashimoto, Present Status and Future Needs: The View from Japanese Industry, in Proceedings of CPC IV, 1991, 1-27.

[40] S.J. Wang, and D.S.H. Wong, Control of reactive distillation production of high-purity isopropanol, Journal of Process Control, 16 (2006) 385-394.

[41] F.O. Barroso-Muñoz, S. Hernández, and B. Ogunnaike, Analysis of Design and Control of Reactive Thermally Coupled Distillation Sequences. 17th European Symposium on Computer Aided Process Engineering - ESCAPE17, (2007) Elsevier, 1-6.

[42] R. Kawathekar, and J.B. Riggs, Nonlinear model predictive control of a reactive distillation column, Control Engineering Practice, 15 (2007) 231-239.

[43] I.K. Lai, S.B. Hung, W.J. Hung, C.C. Yu, M.J. Lee, and H.P. Huang, Design and control of reactive distillation for ethyl and isopropyl acetates production with azeotropic feeds, Chemical Engineering Science, 62 (2007) 878-898.

[44] C. Venkateswarlu, and A.D. Reddy, Nonlinear model predictive control of reactive distillation based on stochastic optimization, Ind. Eng. Chem. Res., 47 (2008) 6949-6960.

[45] S.J. Wang, D.S.H. Wong, and S.W. Yu, Design and control of transesterification reactive distillation with thermal coupling, Computers and Chemical Engineering, 32 (2008) 30303037. 
[46] M.V.P. Kumar and N. Kaistha, Evaluation of ratio control schemes in a two-temperature control structure for a methyl acetate reactive distillation column. Chemical Engineering Research and Design, 87 (2009) 216-225.

[47] A. Bahar, and C. Özgen, State estimation and inferential control for a reactive batch distillation column, Engineering Applications of Artificial Intelligence, 23 (2010) 262-270.

[48] A. Giwa, and S. Karacan, Decoupling PID control of a reactive packed distillation column, International Journal of Engineering Research \& Technology, 1(6) (2012) 1924-1933.

[49] A. Giwa, and S. Karacan, Decoupling model predictive control of a reactive packed distillation column, International Journal of Advances in Science and Technology, 4(6) (2012) 39-51.

[50] A. Giwa, PI and PID Control of a fuel additive reactive distillation process, ARPN Journal of Engineering and Applied Sciences, 11(11) (2016) 6779-6793.

[51] MathWorks. MATLAB, The Language of Technical Computing, The MathWorks, Inc., Natick, 2016.

[52] Stat-Ease, Design Expert, Version 7.0.0, Stat-Ease Inc., Minneapolis, 2005.

[53] Microsoft, Microsoft Excel Version 16.0.4229.1002, Microsoft Corporation, 2016. 